\title{
Natural Family Planning: Knowledge and Practices Assessment Among Couples In Its Utilization: A Study Carried Out In The Bamenda Health District, North West Cameroon
}

\section{Akwanwi Elizabeth Nforlem ${ }^{1}$ Bodzewan Emmanuel Fonyuy ${ }^{2}$}

1Training School for State Registered Nurses-Bamenda.

2Director, Training School for State Registered Nurses-Bamenda; Lecturer, Faculty of Health Sciences, Bamenda University-Cameroon.

\section{ABSTRACT}

People everywhere have developed various means of family planning methods in fertility regulation for reasons such as ensuring better maternal and infant health, paternal care for children, reducing the burden of poverty, improving standards of living, quality education. The rate of population growth worldwide has caused political leaders to encourage national and regional fertility regulation project as vital support for regulation of individual fertility have been evident in all cultures at all-time even in those societies in which social and religious rules have favored the abundant production of children.

The main objective was to assess the knowledge and practice of natural family planning among couples in Bamenda Health District.

The descriptive cross-sectional study design was used in which the investigator collected data from couples on their knowledge in the practice of NFP methods and their findings analyzed.

A sample size of 50 couples was recruited for the study; 50 questionnaires were administered to them within the study period.

A random sampling technique was used, where three catholic churches were selected in the Bamenda Health District. Questionnaires were administered systematically to couples who practice NFP in the reproductive age group in the various churches.

Results show that the high level of awareness of NFP methods did not give a corresponding encouragement to couples in practicing NFP methods. Culture and religion played a major role in a couple's decision to practice NFP methods and this is reflected in the husband's domination in most decisions taking by couples in reproductive health issues. Furthermore, women are found to be more involved in the practice of NFP than men. Both husbands and wives decide on the choice of family planning to be used and comparing following the man and the woman, the man-made the major decisions (26\%) as to (24\%) for the woman. Also following the decision on child spacing, the woman made the major decisions (34\%) as opposed to the man (22\%). On the decision concerning the family size, the man-made the major decisions.

Keywords: Natural Family, Planning methods, Contraception, Couples, Practices, Knowledge, Pregnancy, Childbirth. 


\section{Introduction}

Family planning is the means by which individuals space the process of conception, pregnancy and childbirth at intervals mutually determined by both husband and wife in other to have the desired number of children that they can conveniently maintain. Family planning is also a means of assisting women who are unable to become pregnant become pregnant. People everywhere have developed various means of family planning methods in fertility regulation for reasons such as ensuring better maternal infant health, paternal care for children, reducing the burden of poverty, improving standards of living, quality education. The rate of population growth worldwide have caused political leaders to encourage national and regional fertility regulation project as vital support for regulation of individual fertility have been evident in all cultures at all-time even in those societies in which social and religious rules have favored the abundant production of children(Billing et al, 2010).The need for fertility regulation method to be applied by national and regional authorities were discussed by the united nation population committee in 1947.In 1968,the united nation general assembly and other international bodies affirm family planning as a basic human right (Filstia and Guileband et al., 2009).

However, there were problems associated with the introduction of the modern technological method of family planning ranging from religious, moral and cultural prohibition .There is also the individual aspect to family planning as shown in the record of world fertility survey in 1970; It was discovered that though people have strong desire for fertility regulation in nearly all societies, achieved family size is greater than desired family size

Presently about half of the women in the world who currently have 3 or more children do not wish to have more but they still exist gaps between state desire to control fertility and actual practice (Goldzierher, 2010) from experience, this may be because many women have neither sufficient motivation nor adequate access to the services they will need to make this goal. It may also be due to lack of knowledge in the application of other alternative available such as the natural family planning method.

The various method of family planning can be categories as; the traditional method which involve the use of native objects such as charms, rings, keys, fluid from dead bodies another things for birth control purposes while the modern methods involve IUD,IMPLANT, and Depo-Provera etc. (Delano, 2014) .This is the commonest and mainly advertised form of family planning. However some research results show that most Nigeria couples are non-contraceptive users(suliman,2012).Some of the reasons for the low rate of contraceptive practice according to (Ikchebelu et al., 2015) range from factors such as "fear of side effects, husbands objection, religious and cultural prohibition". It is also on records that whenever a Nigerian woman gets pregnant, she has a 1 in 13 chance of dying mainly due to the poor utilization of modern family planning method (Umar, 2010)

Early marriages have been a regular feature of the African society exposing the adolescents to early sexual activity and pregnancies, both of which can carry major health consequences. Whereas the first birth control clinics was opened in Britain in 1923 
under the auspices of Mary-Stopes, the first spacing clinic was opened in Cameroon only in 1975 at the central maternity of the central hospital Yaoundé.

Family planning objectives were defined for Africa during a regional meeting on family welfare and African development South of the Saharan in Ibadan (Nigeria). In the last years the attitude of the government of Cameroon went from opened hostility towards family planning to tolerance under responsible parenthood and to commitment to family planning as a national policy. Most African countries have followed the same pattern of evolution as Cameroon.

Studies have shown that a good number of me in developing countries approved family planning. The attitude of men doesn't constitute a major obstacle to family planning, but generally, in most developing countries, men have a more reserved attitude towards contraception than women. A study carried out in Cameroon, found that $64 \%$ of men in rural areas of Akonolinga and 63\% in the rural area of Obala were favorable to contraceptives practices. While another study amongst university students in Yaounde showed a favorable attitude in $92 \%$ of unmarried couples and $98 \%$ of married couples. Family planning has nevertheless been more chances of success in developing countries if incorporated into existing health services.

Most researchers and policy makers before now focused on women in their studies of family planning issues with little or no references to their male partners thereby underestimating the role of men as the custodian's family heads and major decision makers in the family and society in general. According to Isoga/Abanihe (2003), the above analysis is evidence to most studies of KAP on family planning which usually focus on the wife family size motivation and contraceptive use rather than husbands. This is similar to Joseph (1993) observation in the study of "medicine and violence against women".

Men decide when, where and how family planning programs should be conducted, so it becomes important to focus on couples in such researches rather than women for and effective change in attitude and motivating couples towards the practice of NFP practice.

Also there seems to be very few studies done so far on NFP and couples involvement in its practice. The available works on family planning is largely based on modern technological methods and women, so providing knowledge about natural family planning methods available to couples as alternative methods is vital in such cases.

The problem resulting from rapid increase in population and the need for fertility regulation to be applied by national and regional authorities led to the introduction of modern method of family planning. The various methods of contraception and their development through the years have been associated with religious, cultural and moral prohibition; traditional values for children in Africa, cases of side effects of the modern methods are some of the problems associated with the issues of family planning.

The desired family size amongst the Nigerian women was estimated at 6 for the average from the natural demographic health survey 2008 studies which means there is every tendency for most of the women to have more than 6 children in their life time considering 
the problem that it is easier said than done. This is because achieved family size is greater than desired family size a gap remains between stated desire to control fertility and actual practice particularly among poorly educated and low income women living in rural areas and urban slums.

Furthermore, certain studies show that although most couple has knowledge about natural family planning but they lack adequate skills to practice it effectively in fertility regulation (Awodu et al, 2011). So how can couples be educated about the types of natural family planning available and how to practice it for effective fertility regulation?

The introduction and use of modern methods of family planning though very useful in some couples for many reasons such as the report of site effect of users of some of the hormonal drugs. Some do not like using these hormonal drugs on religion and cultural prohibition. At times, couples do not agree also on usage. In the search for methods that can be culturally acceptable, tolerated by couples without complaints of site effect, natural family planning and cultural involvement in practice becomes necessary. At this point, it becomes important to study the knowledge, attitude and practice of family planning amongst couples of Bamenda health district. It is relevant to find out the level of awareness of natural family planning methods among couples, how knowledgeable they are in various methods of family planning available and how often do they practice it?

How do couples first come to know about natural family planning and what is the level of corporation between partners in their practice for natural family planning methods? What is their general attitude towards the practice of natural family planning and what are the challenges they face in their use of natural family planning methods? The study therefore seeks to address these research problems.

\section{Main Objective}

To assess the knowledge and practice of natural family planning among couples in Bamenda Health District. This was achieved through the employment of the following objectives.

\section{Specific Objectives}

1. To find out the level of couples awareness in natural family planning methods in Bamenda Health District

2. To assess the attitude towards the practice of natural family planning amongst couples.

3. To examine the extent of gender and spouse involvement in the practice of natural family planning amongst couples

4. To find out challenge couples encounter in the use of natural family planning methods

\section{Hypothesis of the Study}

Couples with adequate knowledge and practical rhythm of natural family planning methods would get the desired family size.

\section{Methodology}

\section{Description of Study Area}

The Bamenda health district is one of the 19 health district of the North West Region of Cameroon. Administratively, the Bamenda health district is divided into three Sub division, namely Bamenda I, II and III Sub divisions. Bamenda1 has one health area, BamendaI I has 13 Health Areas and Bamenda II has 4 health areas. Bamenda 
health District is bounded to the North of Bafut Health District, to the East by Tubah Health District, to the South by Santa Health District, to the Southwest by Bali Health District and to the West by Mbengwi Health District. The Bamenda health district has a population of 422982 inhabitants extracted from 2018 records.

The Bamenda health district has 18 health areas and 42 health facilities.

\section{Study Design}

A descriptive cross-sectional study design was used in which the investigator collected data from couples on their knowledge in practiced of NFP method and their findings analyzed according to the study objectives.

\section{Target Population}

The target population was made up of couples in the Bamenda health district who have been living there for the past one year and practicing various family planning methods.

\section{Study Sample}

The study sample was made up of married couples at the Bamenda health district during the period of data collection.

\section{Sample Size}

A sample size of 50 couples was recruited for the study; 50questionnaires were administered to them within the study period.

\section{Sampling Technique/Procedure}

A random sampling technique was used, where three catholic churches were selected in the Bamenda health district. Questionnaires were administered systematically to couples who practice NFP in the reproductive age group in the various churches.

\section{Data Collection Tool/Instrument}

The instrument that was used for the study was structured questionnaire designated to obtain written answers from the respondents. Open ended and close ended questions were structured to reflect the specific objectives of the study.

\subsection{Pre-testing and Validation of Tools}

The pre-testing was done in the Bafut District Hospital. This was to ensure that the questions were clear and easily understood by the respondents.

After pre-testing, the flaws and lapses were corrected and the questionnaires validated for data collection.

\subsection{Data Collection Procedure/Techniques}

Upon approval of the research topic by the TSSRN Bamenda, a letter of authorization was obtained from the North West Regional delegation of public health. The researcher submitted the authorization alongside the application to carry out the research in different district hospitals. Immediately the permission was granted, the researcher approached each respondent, introduced herself and explained the purpose of the study. She worked with the respondents who were willing to participate in the study. For respondents who could not read or write, the researcher read the questionnaires for them to answer and she wrote down the answers.

\subsubsection{Data Analysis Methods}

The raw facts obtained from the respondents were analyzed using Microsoft word and Microsoft excel. The results were presented as frequencies on tables, pie charts and Bar charts then interpreted accordingly. 


\section{Results}

Socio-Demographic Data

Sex of Respondents

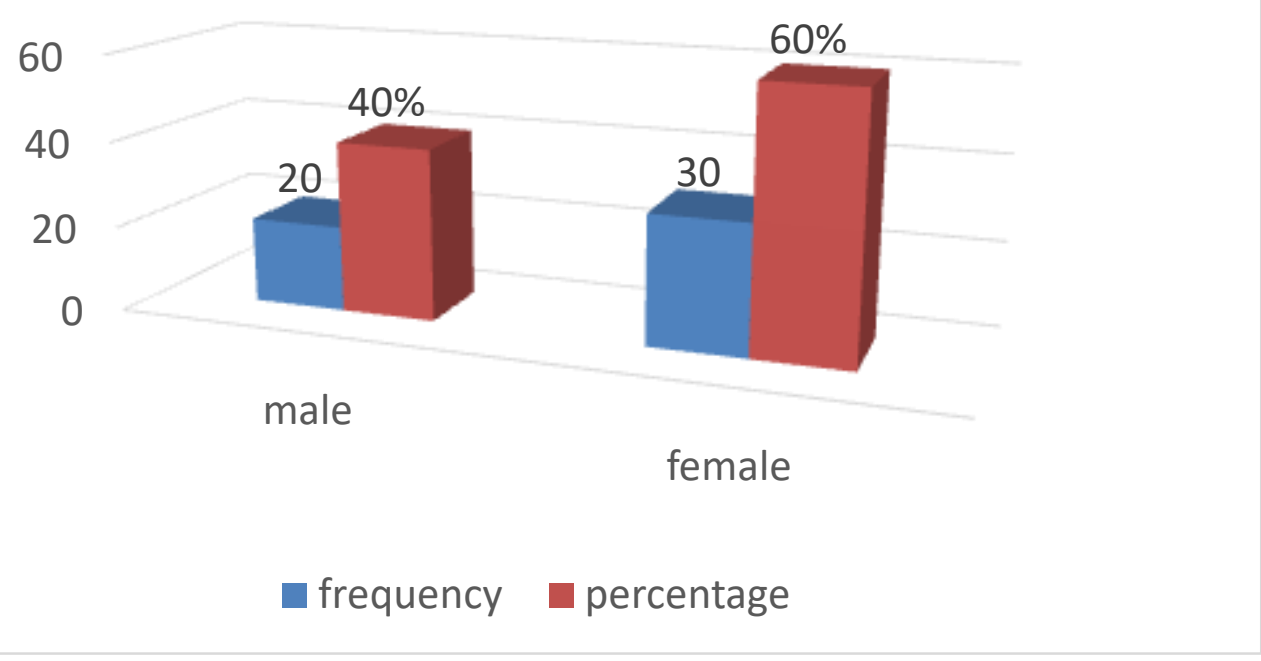

Figure 2: Distribution of respondents according to sex

As it can be seen on figure 2, out of 50 respondents recruited for the study, $60 \%$ were females and $40 \%$ were males.

\section{Age of Respondents}

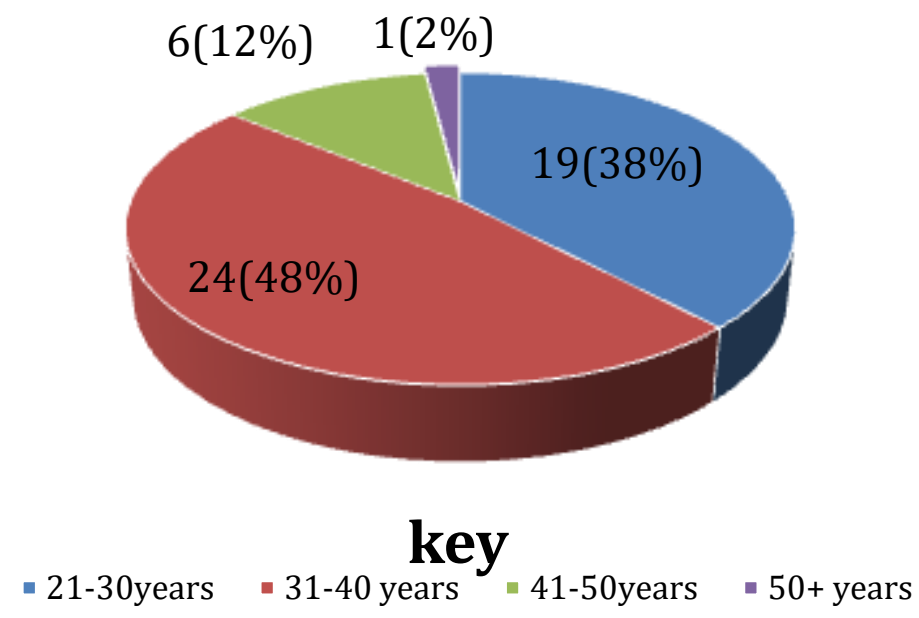

Figure 3: Distribution of respondents according to age

From figure $3,48 \%$ of the respondents were within the ages 31 to 40 years, 38\% fall under the ages 21 to $30,12 \%$ were within 41 to 50 years while $2 \%$ had $>50$ years. 


\section{Marital Status of Respondents}

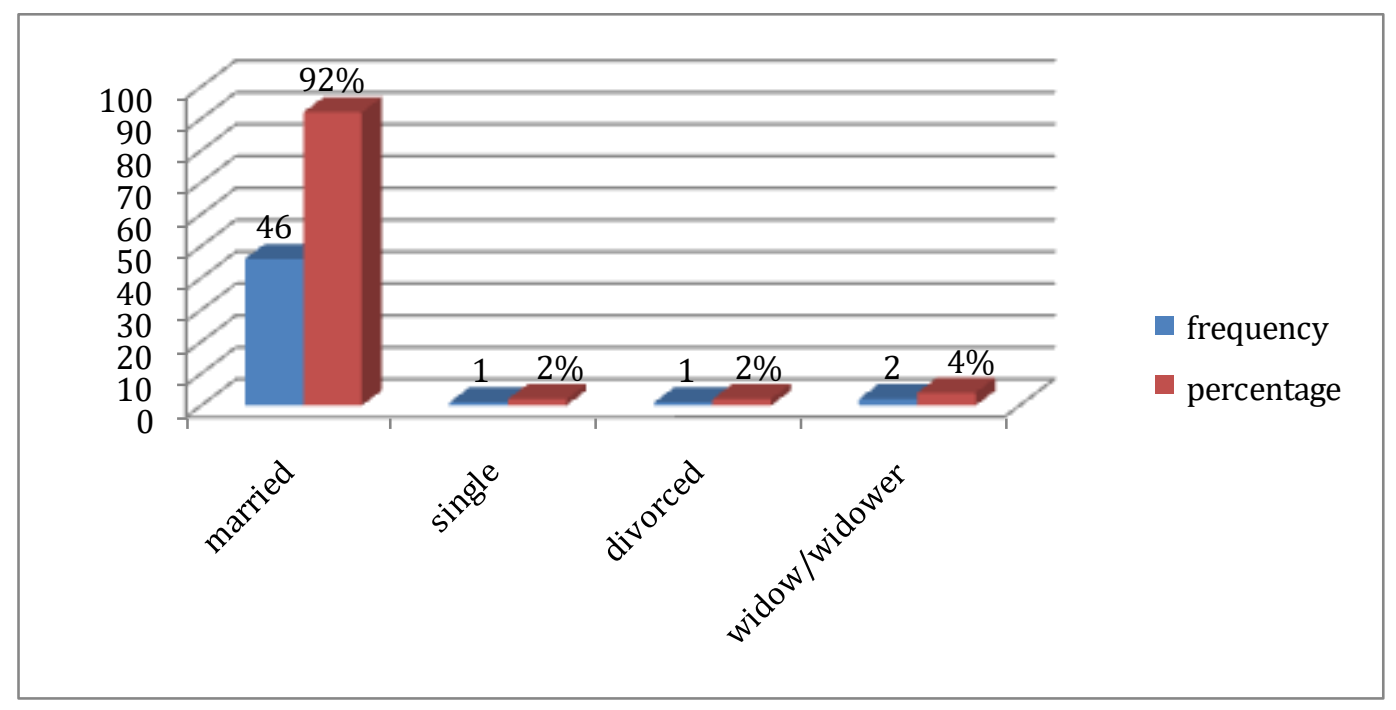

Figure 4: Distribution of respondents according to marital status

From figure 4 , it is clearly seen that $92 \%$ were married, $4 \%$ were widow/widowers and $2 \%$ were single and another $2 \%$ where divorced.

\section{Level of Education}

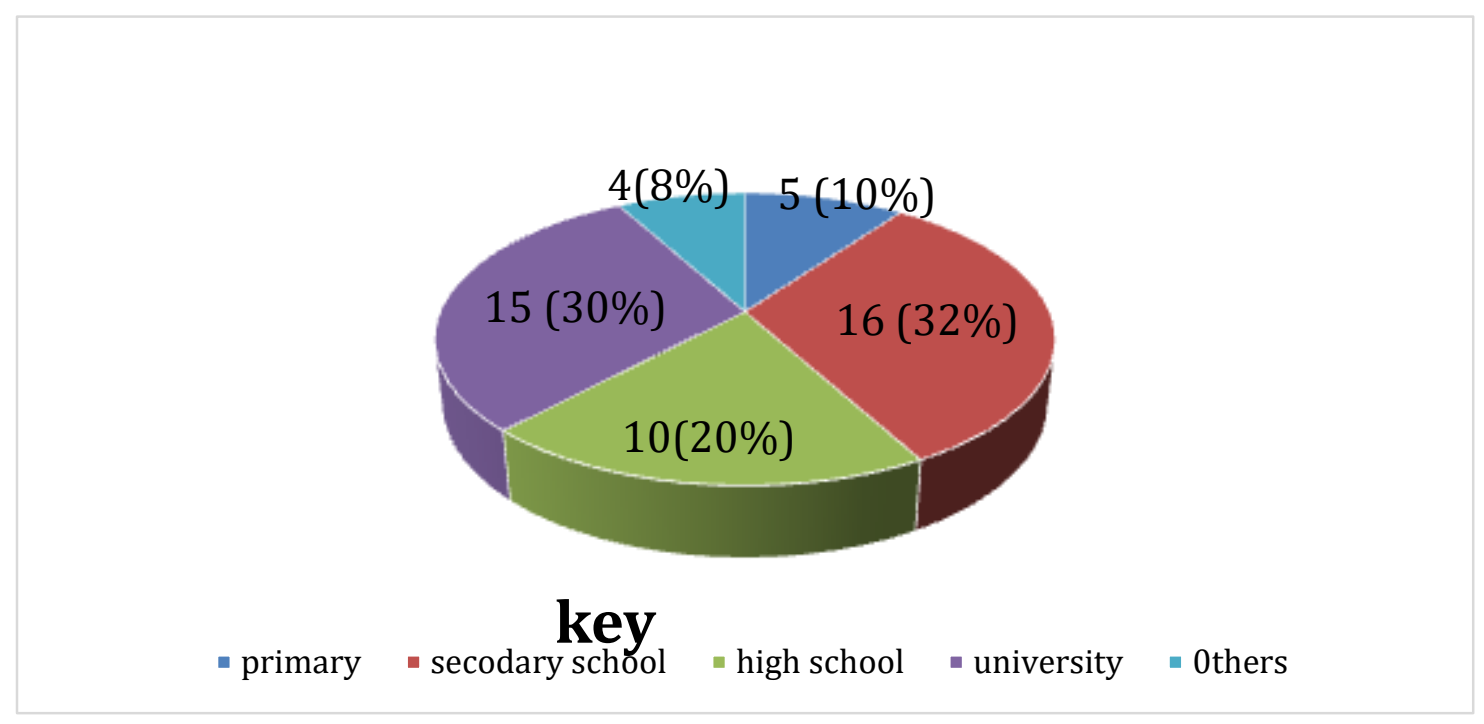

Figure 5: Distribution of respondents according to level of education

It is clearly seen from figure 5 that, majority $32 \%$ of respondent had educational level of secondary school,15\% where university graduate, $20 \%$ had advance level, $10 \%$ primary school while $8 \%$ had others. 


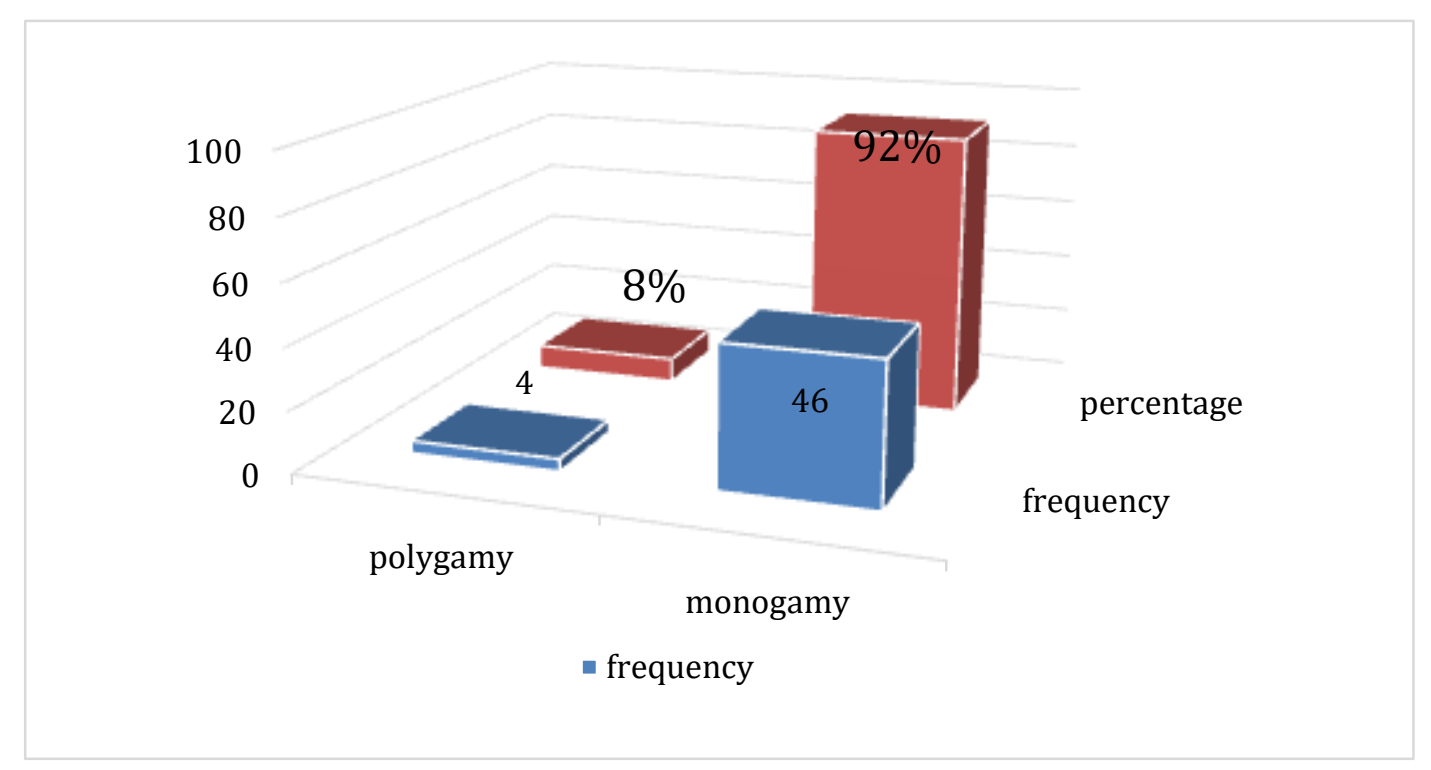

Figure 6: Distribution of respondents according to marital type As can be clearly seen on figure 6, out of the 50 respondents recruited for this study, $92 \%$ practice monogamy while $8 \%$ practice polygamy.

\section{Number of Children Alive}

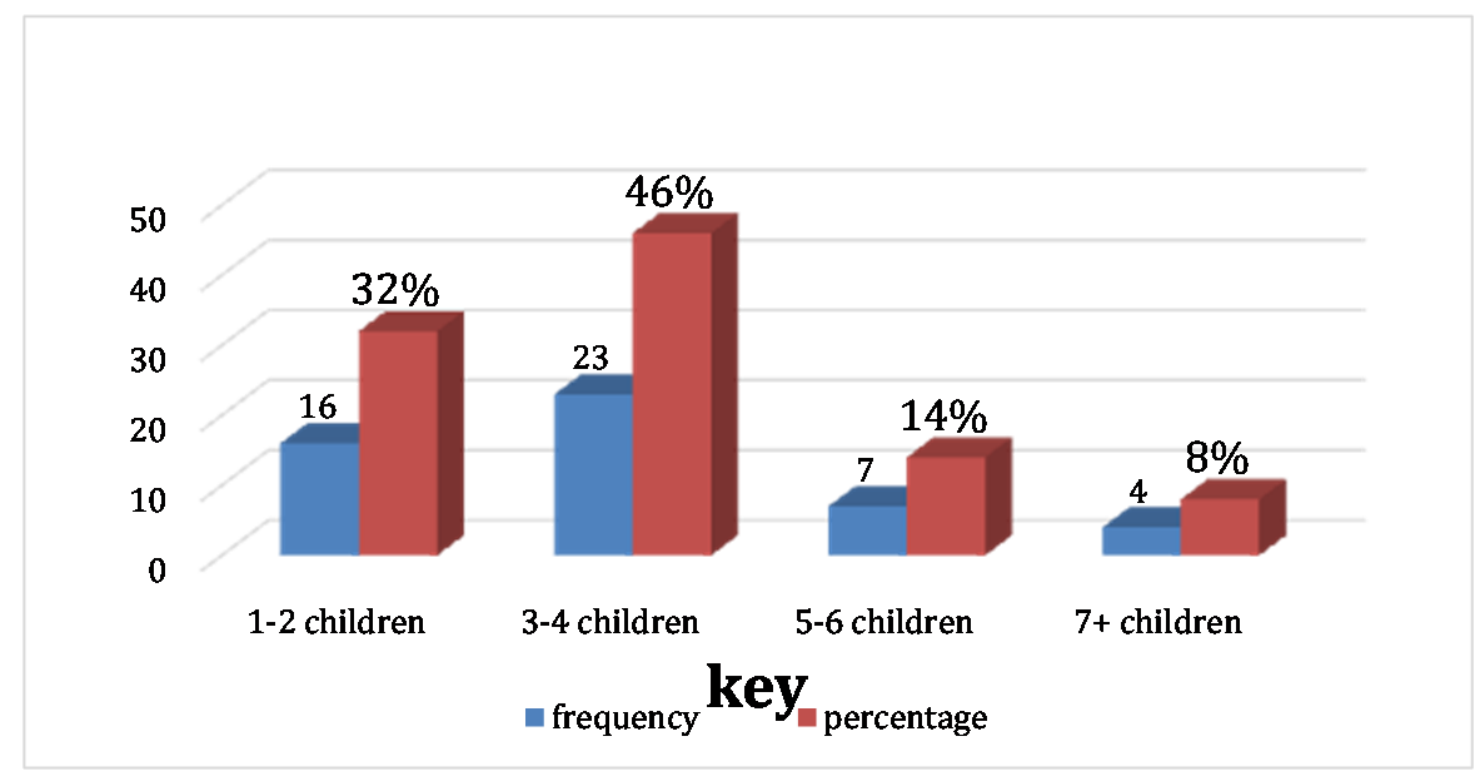

Figure 7: Distribution of respondents according to number of children

From figure 7, majority that is $46 \%$ had 3 to 4 children,32\% had 1 to 2 children,14\% had 5 to 6 and $8 \%$ had $>7$ children. 


\section{Couples Awareness on NFP Method} Spacing between children

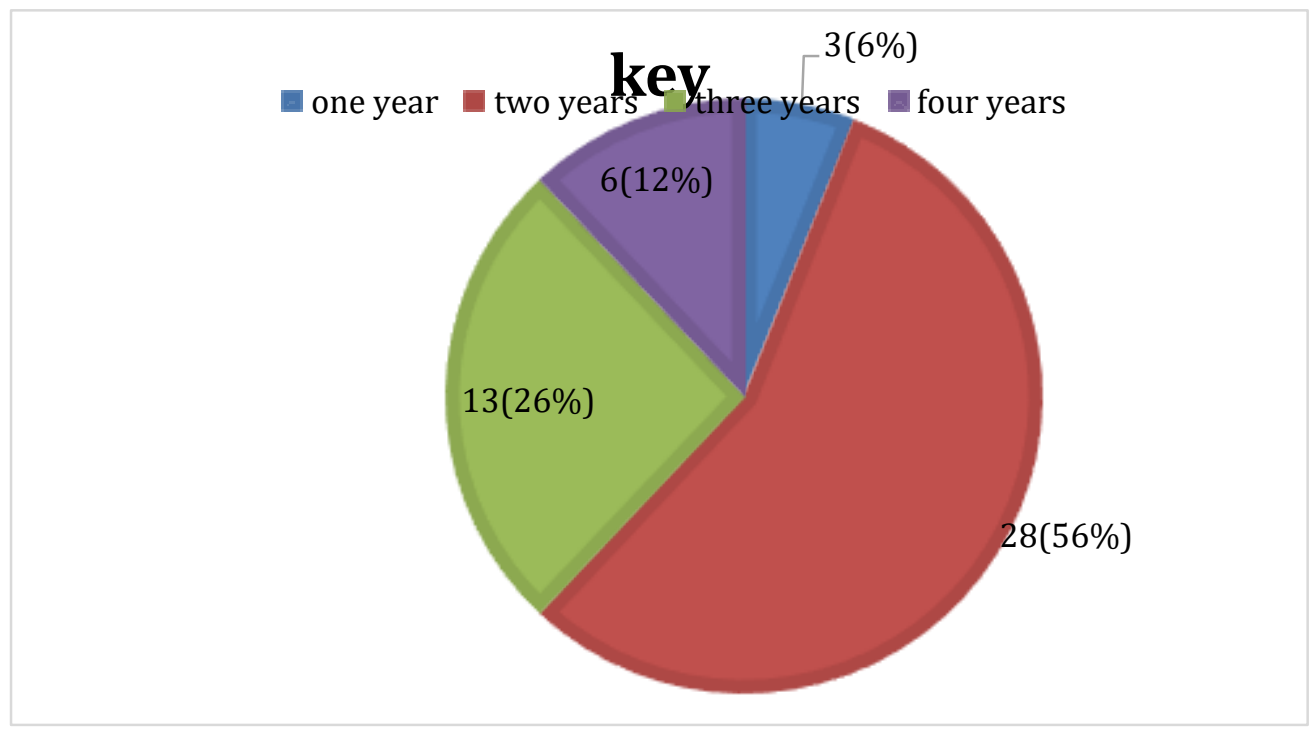

Figure 8: Distribution of respondents according to the spacing between children From the figure 8, majority of the respondents that is $56 \%$ had spacing of two years, 26 had 3 years, 12 had 4 years and a few $6 \%$ had spacing of 1 year.

\section{Desired Family Size}

Table I: Distribution of respondents according to their desired family size.

\begin{tabular}{|l|l|l|}
\hline Response & Frequency & Percentage \\
\hline Two children & 01 & $2 \%$ \\
\hline Three children & 132 & $26 \%$ \\
\hline Four children & 17 & $34 \%$ \\
\hline Five children & 10 & $20 \%$ \\
\hline Six and more children & 09 & $18 \%$ \\
\hline TOTAL & 50 & $100 \%$ \\
\hline
\end{tabular}

As seen in Table I, 34\% desired to have 4 children, 26\% desired 3 children, $20 \%$ desired 5 children, $18 \%$ desired 6 and above while $2 \%$ desired 2 children. 


\section{Previous Family Planning Notions}

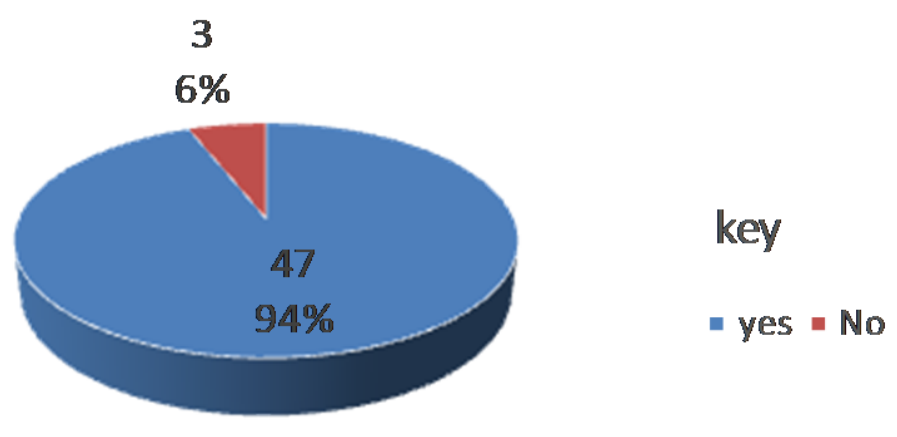

Figure 9: Distribution of respondents according to those who have heard about family planning before

As seen in figure 9 above $94 \%$ of the respondents have heard about family planning and $6 \%$ had no idea about family planning.

Table II: Distribution of respondents to source of first knowledge about family planning.

\begin{tabular}{|l|l|l|}
\hline Source of first knowledge & frequency & Percentage \\
\hline TV/Radio & 3 & $6 \%$ \\
\hline Friends and relative & 14 & $28 \%$ \\
\hline Hospital & 22 & $44 \%$ \\
\hline Journal & 1 & $2 \%$ \\
\hline Others & 10 & $20 \%$ \\
\hline TOTAL & $\mathbf{5 0}$ & $\mathbf{1 0 0 \%}$ \\
\hline
\end{tabular}

The table shows that $44 \%$ had their first knowledge on family planning in hospital, $28 \%$ from relative and friends, and 20\% from other sources, $6 \%$ from TV / RADIO and 2\% from journals. 


\section{Attitude Toward the Practice of NFP Among Couples Use of family planning in child spacing}

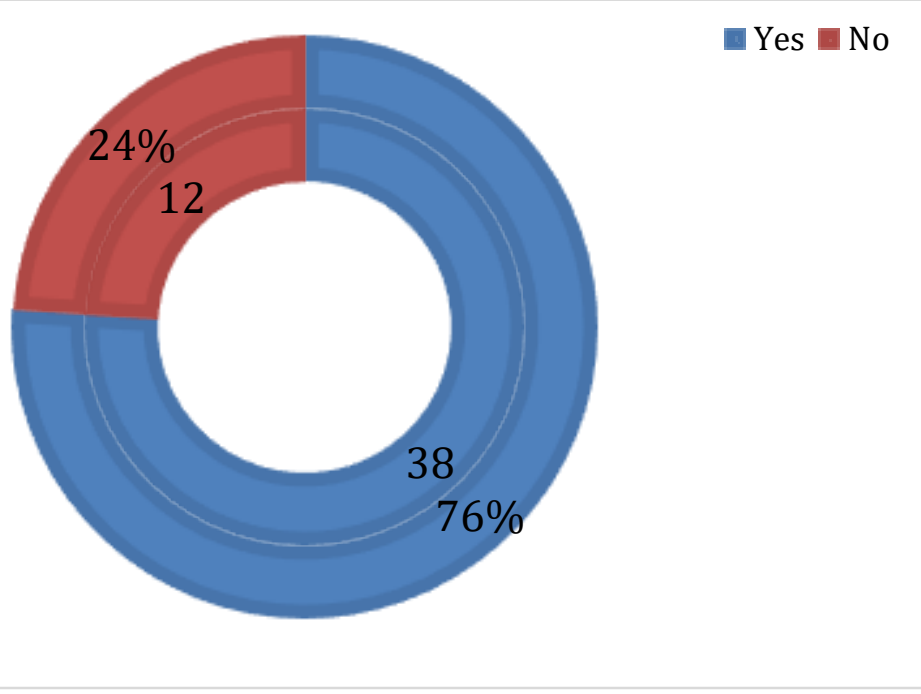

Figure 10: Distribution of respondents according to use of family planning in child spacing Following figure $11,76 \%$ of the respondents said they used family planning for child spacing while $24 \%$ said they did not use family planning for child spacing.

\section{Various methods used in natural family planning}

Table III: Distribution of respondents according to the various method they use in natural family planning and those who use other methods.

\begin{tabular}{|c|c|c|}
\hline Response & Frequency & Percentage \\
\hline Monitor menstrual cycle & 9 & $18 \%$ \\
\hline Abstinence & 14 & $28 \%$ \\
\hline Calendar method & 8 & $16 \%$ \\
\hline Withdrawal method & 13 & $26 \%$ \\
\hline Temporal separation & 4 & $8 \%$ \\
\hline Basal body temperature & 2 & $4 \%$ \\
\hline
\end{tabular}




\begin{tabular}{|c|c|c|}
\hline TOTAL & 50 & $100 \%$ \\
\hline \multicolumn{3}{|l|}{ Others } \\
\hline Jadelle & 03 & $27.3 \%$ \\
\hline Pills & 02 & $18.2 \%$ \\
\hline IUCD & 02 & $18.2 \%$ \\
\hline Deposhot & 01 & $9.1 \%$ \\
\hline Condom & 03 & $27.3 \%$ \\
\hline TOTAL & 11 & $100 \%$ \\
\hline
\end{tabular}

As illustrated in table 2, 28\% of the respondents practiced abstinence during the fertile period, 26\% practiced withdrawal method and 18\% monitor their menstrual cycle. For those who used other methods, 27\% of them used Jadelle and condom, 18\% used pills and IUCD and 9\% used Depo shot. Extend of Gender and Spouse Involvement in the Practice of NFP Among Couples Use of natural family planning to prevent or delay pregnancy

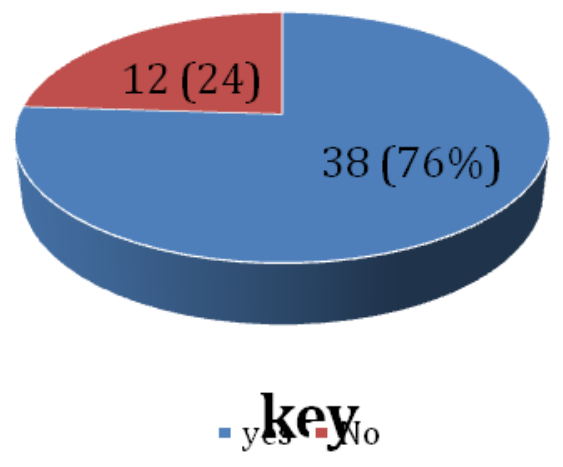

Figure 11: Distribution of respondents according to their use of natural family planning to prevent or delay pregnancy

This figure shows that $76 \%$ of the respondents used natural family planning to prevent or delay pregnancy while $24 \%$ do not use natural family planning to delay or prevent pregnancy. 


\section{Discussion with spouse on family planning}

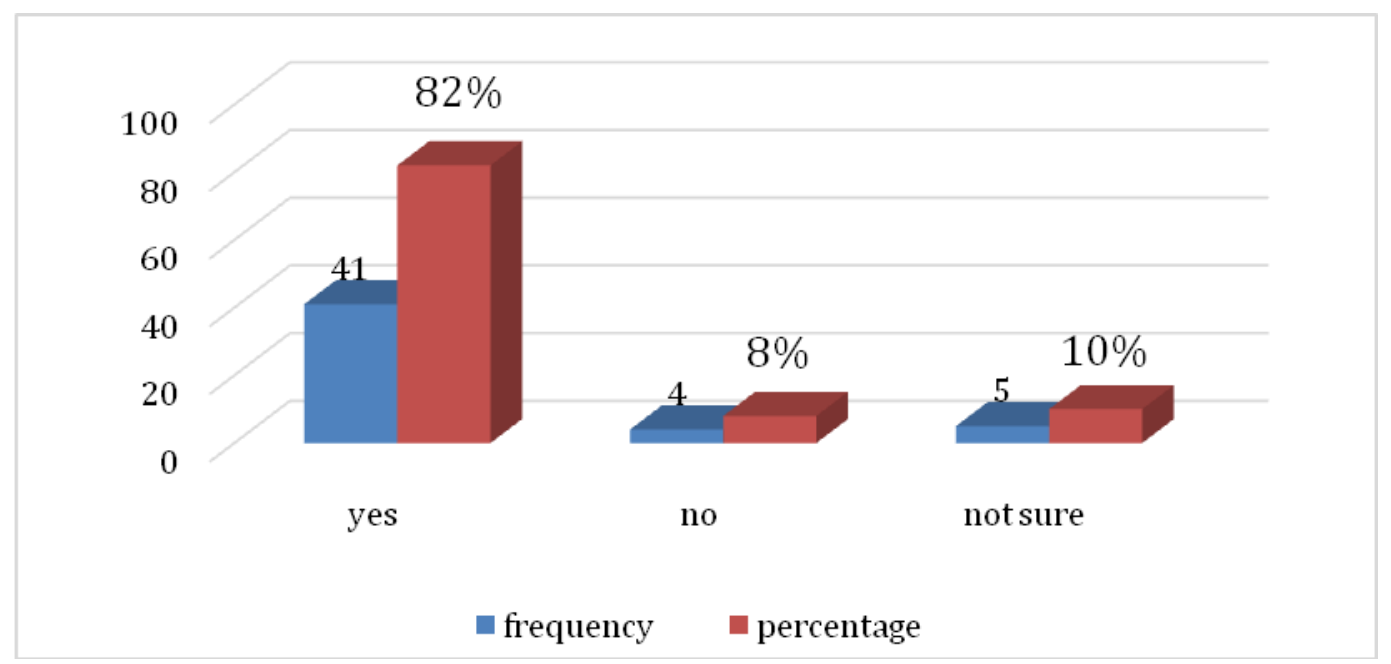

Figure 12: Distribution of respondents according discussion with spouse on family planning This diagram shows that $82 \%$ discussed about family planning with spouse, $10 \%$ said they were not sure while $8 \%$ said they do not discuss it at all.

\section{Choice of family planning to be used}

Table IV: Distribution of respondents on who makes the choice of family planning to be used, decides on child spacing, decides on family size, who is more involved in it practice.

\section{Response \\ frequency \\ Percentage}

Choice of family planning to be used

\begin{tabular}{|l|l|l|}
\hline Woman & 12 & $24 \%$ \\
\hline Man & 13 & $26 \%$ \\
\hline Both couples & 25 & $50 \%$ \\
\hline TOTAL & $\mathbf{5 0}$ & $\mathbf{1 0 0 \%}$ \\
\hline Decision on child spacing & 17 & $34 \%$ \\
\hline Woman & 11 & $22 \%$ \\
\hline Man & 22 & $44 \%$ \\
\hline Both & $\mathbf{5 0}$ & $\mathbf{1 0 0 \%}$ \\
\hline TOTAL & & \\
\hline
\end{tabular}


Decision on family size

\begin{tabular}{|l|l|l|}
\hline Woman & 9 & $18 \%$ \\
\hline Man & 20 & $40 \%$ \\
\hline TOTAL & 21 & $42 \%$ \\
\hline More involved in practice of natural family planning & $\mathbf{5 0}$ & $\mathbf{1 0 0 \%}$ \\
\hline Woman & 36 & $72 \%$ \\
\hline Man & 8 & $16 \%$ \\
\hline Both & 6 & $12 \%$ \\
\hline TOTAL & $\mathbf{5 0}$ & $\mathbf{1 0 0} \%$ \\
\hline
\end{tabular}

This table shows that amongst the challenges encountered by the respondent during their practice of natural family planning, $28.6 \%$ said miscalculation of the menstrual cycle, $16.7 \%$ said it led to quarreling, inability to control self during unsafe periods and 14.3\% said inability to satisfy sexual desire during unsafe period. For those who had no challenges 46.7 said they only had children when they want to, $20 \%$ said they face no challenges because they both took the decision before going for it while $13 \%$ said it has no side effect and always available, and they also had correct spacing of their children.

\section{Discussion of Findings \\ Socio-Demographic data}

The study involved married couples, their knowledge, and practice of NFP. This study revealed that majority of the respondents was within the age range of 31 to 40 years. This shows that most respondent was within the reproductive age and as the study population consisted of married couples is ages were as expected. Concerning status, the majority $(92 \%)$ of the couples were living together while some divorced and some were widows and widowers. Most of the couples (92\%) practiced monogamous marriages while some practiced polygamy. Concerning the respondent level of education, the majority $(32 \%)$ of them had attained a secondary level of education which is a good level for one to be able to understand the various methods of NFP as compared to those who didn't go to school and those who ended at the primary school level. $46 \%$ of the respondents had 3 to 4 children, $8 \%$ of them had 7 and above.

\section{Respondents' Knowledge on NFP}

The major findings of the study were summarized as followed according to the study objectives. The study found out that there was a very high level (94\%) of awareness of NFP methods among the 
couples with two major sources of information about NFP method identified; notably from hospital, friends and relatives. Also the study revealed that husbands take the highest decision (40\%) concerning desired family size than the wives (18\%) and the woman did not see that as a problem due to the influence of socio-cultural beliefs. This is in line with the saying that the man is the head in the family and so he takes the major decisions in the family.

\section{Practice of NFP}

Results from the study shows that abstinence and withdrawal methods were the commonest form of NFP methods used by couples. Economic factors and the cultural beliefs about the harmful effect of contraceptives drugs were the main reasons given by respondents for the choice of NFP methods. However, this method responded on the awareness and ability of couples to identify the fertile and unfertile phase of each menstrual cycle and also require cooperation between the couples to abstain from, or to have sexual intercourse, depending on whether they are trying to avoid or achieve pregnancy. Furthermore the study revealed that there are women who approves and wanted to practice NFP but cannot because of the Uncooperating attitude of husbands while some lack the basic understanding needed to practice NFP methods.

\section{Gender and Spousal Involvement in the Practice of NFP}

Furthermore findings shows that both husbands and wives take the decision on the choice of family planning to be used and comparing following the man and the woman, the man made the major decisions (26\%) as to $(24 \%)$ for the woman. Also following the decision on child spacing, the woman made the major decisions (34\%) as opposed to the man $(22 \%)$. On the decision concerning the family size, the man made the major decision. While on the practice of natural family planning the woman is more involved in the practice $(72 \%)$ than the man (16\%). This is in line with Joseph (1993) observation which says men decide when, where and how family planning programs should be conducted.

\section{Challenges Encountered}

The findings indicated that most couples (68\%) encountered challenges in the practice of NFP. These challenges ranges from spouse desiring to have sex during unsafe periods leading to quarreling between spouse $(16.7 \%)$, miscalculation of menstrual cycle (28.6\%), inability to control self during sexual arousal (16.7\%), alteration in menstrual cycle (7.1\%), inability to satisfy sexual desires during unsafe periods (14\%). This is in line with Awodu et al (2011) studies which show that although most couples had knowledge about NFP they lack adequate skills to practice it effectively. In this case, achieved family size is greater than desired family size.

\section{Conclusion}

The high level of awareness of NFP method do not give a corresponding encouragement to couples in practicing NFP methods; the desired number of children for reasons of social security. Culture and religion played major role in couple's decision to practice NFP methods and this is reflected in the husband's domination in most decisions taking by couples in reproductive health issues such as NFP matters. Furthermore, women are found to be more involved in the 
practice of NFP than men. Concerning awareness of NFP methods $94 \%$ of the couples were aware of NFP and also from findings both husbands and wives takes the decision of family planning to be used. Both husbands and wives take the decision on the choice of family planning to be used and comparing following the man and the woman, the man made the major decisions (26\%) as to $(24 \%)$ for the woman. Also following the decision on child spacing, the woman makes the major decisions (34\%) as opposed to the man $(22 \%)$. On the decision concerning the family size, the man made the major decision.

\section{References}

1. Adamu S A (2011):Presentation by the Kaduna state honorable commissioner of information and home affairs to senior Executive course no 33,study group II of the national institute of policy and strategic studies (NIPSS) pg2 and 3 Kuru,Kaduna.

2. Agbese A (2011). Northern Nigeria now embracing family planning.The Daily Trust.

3. Billing J (2012). The guest-leading to the discovery of the Billing Ovulation method. Bulletin of Ovulation Method Research and Reference Center of Australia vol 29 No1 pg 28.

4. Delano E (2014) Guide to family planning spectrum book Ltd Ubadan.

5. Filstie M S Guileband J (2009). Contraception, Science and Practice Butterworth London.

6. Godswill J U 2008. The political economy of maternal and child health in Nigeria Dept of sociology. ABU Zaria Journal of Social Sciencevol 1.

7. Eyong J E (2012). Criminal victimization and the reporting of crime in Kaduna state towards integrating the victim of crime into criminological discourse current research journal of social science.

8. Ijadunole $\mathrm{K}$ T AfolabioT(2010). Male involvement in family planning decision making.

9. KejaMadalene Yang Mange (1991). The knowledge attitude and practice of contraceptive among university students in Cameroon MD Thesis-Cuss University of Yaounde.

10. Leo R (2011) F G Begins contraceptive distribution. The Daily Trust.

11. Nigeria and demographic health survey national population commission. Federal republic of Nigeria Abuja (2009) USAID, UNFPA.

12. Olisemeka C F and Salim A (2011) Gender needs assessment for Kaduna metropolis Nigeria.

13. PATHS (2008) supporting Kaduna's health reform agenda (Nigeria D F I D).

14. Population reference Bureau world population data sheet 2010 pg 10 population health and environment data and estimates for the countries and regions of the world Washington DC USA.

15. 2008 Demographic and health survey fact sheet NW zone NPC Abuja Nigeria USAID UNFPA.

How to cite this Article: Akwanwi Elizabeth Nforlem; Natural Family Planning: Knowledge and Practices Assessment Among Couples In Its Utilization: A Study Carried Out In The Bamenda Health District, North West Cameroon; Int. Res. Med. Health Sci., 2019; 2(4):26-41.

Source of Support: Nil, Conflict of Interest: None declared.

Received: 25-06-2019; Revision: 18-07-2019; Accepted: 27-08-2019 